\title{
PEMBUATAN MEMBRAN SELULOSA ASETAT DARI SELULOSA PELEPAH POHON PISANG
}

\author{
[The Production of Cellulose Acetate Membrane from Stem of Banana Cellulose] \\ Dina Apriana Putri Husni ${ }^{1}$, Erwin Abd. Rahim ${ }^{1}$, Ruslan $^{1}$ \\ 1 Jurusan Kimia Fakultas MIPA, Universitas Tadulako \\ Jl. Soekarno Hatta Km.9, Kampus Bumi Tadulako Tondo Palu, Telp. 0451- 422611
}

*)Coresponding author: dinaapriana26@gmail.com

Diterima 17 Desember 2017, Disetujui 13 Februari 2018

\begin{abstract}
The aim of this research is to find out the ratio of polyethylene glycol in cellulose cetate that produce the best cellulose acetate membrane. Cellulose was produced by extracting stem of banana. Cellulose acetate was obtained in cellulose synthesis. The membrane was templated by dissolving cellulose acetate in the acetone at ratio of $1: 45$ (b/v) by adding PEG as plasticizer $(0 ; 2 ; 4 ; 6$; and $8 \%)$. Thickness, tensile strenght, and elongation of the membrane were tested by using micrometer and universal testing machine, respectively. The rendement of cellulose was $62.5 \%$, while the synthezised cellulose acetate has rendament of $50 \%$. The molecular weight of cellulose acetate was $24.961,48$ $\mathrm{g} / \mathrm{mol}$. The best membrane characteristic was obtained at $8 \%$ of PEG with thickness of $0,0206 \mathrm{~mm}$, tensile stenght of $20.29 \mathrm{Mpa}$, and elongation of $3 \%$.
\end{abstract}

Key word : Cellulose, Cellulose Acetate, Membrane, PEG

\begin{abstract}
ABSTRAK
Penelitian ini bertujuan untuk mengetahui penambahan rasio polietilen glikol pada selulosa asetat yang menghasilkan karakteristik membran selulosa asetat terbaik. Selulosa diperoleh dari proses ekstraksi pelepah pohon pisang. Selulosa asetat diperoleh dari sintesis selulosa. Pencetakan membran dilakukan dengan melarutkan selulosa asetat ke dalam pelarut aseton 1:45 (b/v) dan ditambahkan pemlastis PEG dengan variasi $0 ; 2 ; 4 ; 6$; dan $8 \%$. Membran diuji ketebalannya menggunakan micrometer sedangkan untuk kuat tarik dan elongasi diuji dengan Universal Testing Machine. Rendemen selulosa yang diperoleh adalah $62,5 \%$. Rendemen selulosa asetat dari hasil sintesis adalah $50 \%$. Berat molekul selulosa asetat $24.961,48 \mathrm{~g} / \mathrm{mol}$. Karakteristik membran terbaik diperoleh pada penambahan PEG $8 \%$ yang memiliki ketebalan $0.0206 \mathrm{~mm}$, kuat tarik sebesar 20,29 $\mathrm{MPa}$, dan elongasi sebesar $3 \%$.
\end{abstract}

Kata Kunci : Selulosa, Selulosa Asetat, Membran, PEG 


\section{LATAR BELAKANG}

Teknologi terbarukan merupakan teknologi yang sedang berkembang pesat dan menjadi pusat perhatian dunia saat ini. Salah satu teknologi terbarukan yang sedang berkembang adalah teknologi pemisahan demgan menggunakan membran yang memanfaatkan bahan terbarukan yaitu polimer alam (Lankaster, 2002).

Pemisahan dengan membran merupakan teknologi yang banyak dikembangkan sebagai alternatif pengganti proses pemisahan konvensional. Teknologi tersebut memiliki kelebihan dibandingkan dengan teknik konvensional, seperti energi yang dibutuhkan rendah, dapat berlangsung secara kontinyu, prosesnya dapat dikombinasikan dengan proses pemisahan yang lain, tidak membutuhkan banyak zat aditif, cocok untuk senyawasenyawa yang tidak tahan panas, dan tidak menghasilkan limbah (Nunes, 2001). Dengan keunggulan tersebut teknologi membran telah banyak diaplikasikan dalam berbagai bidang, diantaranya di bidang industri, kimia dan farmasi, bidang pengolahan limbah dan teknologi lingkungan bidang pengolahan minyak, yaitu proses pengolahan vegetable oil (Coutinho, 2009). Namun, di Indonesia perkembangan teknologi membran tidak secepat di negara lain karena material membran yang masih harus diimpor.

Pada dasarnya, material membran dapat berasal dari keramik, silika, zeolit, logam, kaca, atau polimer (Drioli, et al., 2010). Biopolimer umumnya banyak dikembangkan sebagai bahan dasr membrane, seperti kitosan (Astuti, 2008), agar-agar (Setyaningrum et al., 2017), dan selulosa (Yuan et al., 2009). Selulosa pada khususnya berpotensi besar sebagai bahan alternatif material membran ataupun bentuk turunannya seperti selulosa asetat. Indonesia memiliki kekayaan sumber daya alam sebagai potensi bahan selulosa diantaranya adalah serat limbah pohon pisang yang mengandung selulosa hingga 63\% (Small, 1954 dalam Wijaya, 2002). Merujuk pada pemanfaatan batang pisang yang sangat kurang, maka serat limbah pohon pisang dapat dimanfaatkan sebagai alternatif bahan dasar pembuatan selulosa asetat.

Selulosa asetat memiliki keunggulan sebagai bahan dasar pembuatan membran karena memiliki struktur asimetrik dengan lapisan aktif yang sangat tipis, dapat menahan bahan terlarut pada lapisan pendukung yang kasar, tahan terhadap terjadinya pengendapan, menghasilkan keseimbangan sifat hidrofilik dan hidrofobik (Kumano \& Fujiwara , 2008). Membran selulosa asetat dari limbah pelepah pohon pisang memilki sifat biodegradable, tetapi sifat mekaniknya kurang optimal sehingga usia guna membran menjadi singkat. Oleh karena hal tersebut, dibutuhkan zat aditif untuk memperbaiki sifatnya, seperti pemlastis atau senyawa yang memungkinkan plastik yang dihasilkan 
tidak mudah rapuh dan kaku (Darni et al., 2009). Salah satu pemlastis yang sering digunakan adalah polietilen glikol (PEG) karena tidak beracun, biokompatibel, hidrofilik, memiliki fleksibiltas yang tinggi, antifoaming agent, dan antifouling (Apriliani, 2010 dan Su et al., 2009). Penambahan PEG pada membran dapat menghasilkan membran dengan pori yang lebih kecil dan lebih teratur Muliawati (2012) serta dapat meningkatkan nilai fluks membran (Yang et al., 2001).

Apriliani (2010) menggunaan PEG pada membran kitosan dan menujukkan peningkatan permebilitas membran PEG 2:1 dan 3:1 berturut-turut memberikan nilai sebesar $0,805 \mathrm{~L} / \mathrm{m}^{2}$ jam dan $2,617 \mathrm{~L} / \mathrm{m}^{2}$ jam pada tekanan $1 \mathrm{~atm}$. Fadillah (2003), Mohammadi dan Saljoughi (2009) serta Saljoughi (2010) melaporkan bahwa laju permeasi membran selulosa asetat komersil akan meningkat dengan penambahan PEG. Rini dkk (2007) juga melaporkan bahwa semakin banyak penambahan PEG, maka semakin kecil pori-pori membran silika sekam padi, sehingga lebih efektif digunakan pada dekolorisasi air limbah batik. Berdasarkan hasil penelitian tersebut maka perlu kajian tentang membran selulosa asetat berbasis selulosa pelepah pisang dengan penambahan PEG.

\section{METODE PENELITIAN}

\section{Bahan dan Peralatan}

Bahan yang digunakan yaitu limbah pelepah pohon pisang kepok bagian luar, natrium hidroksida, natrium hipoklorit, asam sulfat, asam asetat glasial, asam asetat anhidrat, aquades, aseton, polietilena glikol.

Peralatan yang digunakan dalam penelitian ini adalah alat refluks, blender, ayakan 60 mesh, spektrofotometer FTIR, viscometer Ostwald, hot plate WiseStir MSH 20-D, stirrer, oven Memmert, neraca analitik merk Adventure TM Ohaus, kertas saring, desikator, micrometer Krisbow, gegep, oven, plat kaca $25 \times 30 \mathrm{~cm}$ dan alat- alat gelas yang biasa digunakan di laboratorium.

\section{Prosedur Kerja}

\section{Preparasi Sampel (Ningsih et al., 2014)}

Pelepah pohon pisang kepok dicuci bersih dengan air mengalir. Selanjutnya ditiriskan, kemudian dipotong kecil-kecil sampai sampel pelepah pohon pisang kepok kering. Sampel kering digiling dan diayak dengan ayakan berukuran 60 mesh.

\section{Ekstraksi selulosa (Rosli et al., 2013)}

Sampel pelepah pohon pisang sebanyak 10 gram ditambahkan $250 \mathrm{~mL}$ natrium hidroksida $4 \%$ (b/v) dan direfluks pada suhu $70^{\circ} \mathrm{C}$ selama 2 jam. Kemudian dicuci dengan aquades sampai $\mathrm{pH}$ netral. Setelah itu dilakukan proses pemutihan dengan menggunakan $250 \mathrm{~mL}$ natrium hipoklorit $1,7 \%$ (v/v) pada suhu $70^{\circ} \mathrm{C}$ selama 4 jam. Kemudian dicuci dengan aquades sampai $\mathrm{pH}$ netral. Rasio sampel dalam larutan adalah 1:25 $(\mathrm{g} / \mathrm{mL})$. Setiap perlakuan sampel dilakukan dua kali dan 
sampel dicuci menggunakan akuades. Kemudian dikeringkan dalam oven pada suhu $70^{\circ} \mathrm{C}$ selama 4 jam. Kemudian dihaluskan menggunakan lumpang dan alu. Sehingga diperoleh serbuk kering selulosa. Sampel yang dihasilkan kemudian diuji karakterisasinya menggunakan FTIR.

\section{Sintesis selulosa asetat (Bahmid et al., 2014) Khaswar dan Tutus, 2014)}

15 gram selulosa ditambahkan 150 $\mathrm{mL}$ asam asetat glasial (1:10) dan diaduk pada suhu $38^{\circ} \mathrm{C}$ selama 60 menit. Selulosa ditambahkan 2\% (v/v) asam sulfat p.a dan diaduk pada suhu $38^{\circ} \mathrm{C}$ selama 45 menit. Hasil aktivasi ditambahkan $100 \mathrm{~mL}$ asam asetat anhidrida p.a kemudian diaduk pada suhu $38^{\circ} \mathrm{C}$ selama 45 menit. Hasil asetilasi ditambahkan aquades sebanyak $10 \mathrm{~mL}$ dan asam asetat glasial $20 \mathrm{~mL}$ dan diaduk pada suhu $50^{\circ} \mathrm{C}$ selama 30 menit. Larutan kemudian disentrifugasi. Endapan yang diperoleh dimasukkan ke dalam $500 \mathrm{~mL}$ aquades sehingga terbentuk serpihan selulosa asetat berwarna putih. Serpihan selulosa asetat kemudian disaring menggunakan corong dan dicuci dengan aquades sampai bau asam hilang. Kemudian dikeringkan dalam oven pada suhu $55^{\circ} \mathrm{C}$ selama 4 jam. Sehingga diperoleh serbuk kering selulosa asetat. Sampel yang dihasilkan kemudian diuji karakterisasinya menggunakan FTIR dan dilakukan penentuan berat molekul selulosa asetat.

\section{Penentuan Berat Molekul Selulosa Asetat}

Penentuan berat molekul selulosa asetat menggunakan alat viskometer oswald. Larutan selulosa asetat disiapkan dengan konsentrasi 0,$0 ; 0,05 ; 0,1 ; 0,15$; 0,2 dan $0,25 \mathrm{~g} / 25 \mathrm{~mL}$ larutan aseton. Sejumlah volume larutan tersebut dimasukkan ke dalam viskometer oswald dan ditentukan waktu alirnya dengan pengukuran berulang. Bobot molekul dapat dihitung dengan menggunakan persamaan Mark-Houwink:

Viskositas relatif $\quad \eta r=\eta / \eta o \cong t / t o$

Viskositas spesifik $\eta s p=\eta r-1$

Viskositas intrinsik $[\eta]=(\eta \mathrm{sp} / \mathrm{c})$

$$
\eta=K M^{\beta}
$$

$$
\begin{aligned}
\text { dimana: } & K=1,49 \times 10^{4} \mathrm{ml} / \mathrm{g} \\
\alpha & =0.82 \\
\eta & =\text { viskositas zat } \\
\eta_{0} & =\text { viskositas pelarut } \\
\mathrm{t} & =\text { waktu alir zat (dalam detik) } \\
\mathrm{t}_{0} & =\text { waktu alir pelarut }
\end{aligned}
$$

\section{Pembuatan membran selulosa asetat (Modifikasi metode Pasla, 2006)}

Pembuatan membran melalui fasa inversi dengan cara pencelupan. Tahap pertama sebanyak 10 gram selulosa asetat dilarutkan dalam $45 \mathrm{~mL}$ aseton dan diaduk menggunakan stirer hingga tercampur rata. Pemlastis Polietilen glikol (PEG) ditambahkan ke dalam larutan dengan variasi $0 ; 2 ; 4 ; 6$ dan $8 \%$ dari bobot selulosa asetat. Siapkan kaca yang berukuran $20 \times 15 \mathrm{~cm}$ yang telah diberi selotip pada kedua sisi yang berhadapan. larutan polimer dituangkan ke atas 
penampang kaca tersebut lalu dicetak sebagai lapisan tipis dengan cara menekan dengan batang stainless lalu menarik larutan polimer tersebut, sampai diperoleh lapisan tipis. Lapisan tipis ini menempel pada kaca dan dibiarkan selama 1 menit. Kemudian, penampang kaca direndam di dalam air sampai lapisan tipis yang menempel terlepas dari penampang kaca. Selanjutnya, lapisan tipis tersebut dikeringkan

\section{Pengujian karakteristik membran.}

\section{Uji Ketebalan (Akili et al., 2012)}

Ketebalan film diukur menggunakan micrometer (ketelitian 0,001 mm) dengan cara menempatkan film di antara rahang micrometer. Untuk setiap sampel film yang akan diuji, ketebalan diukur pada lima titik yang berbeda, kemudian dihitung reratanya.

\section{Sifat Mekanik (ASTM 882-91, 1996)}

Penentuan kuat tarik dan pemanjangan diuji menggunakan Universal Testing Machine. Spesimen film dipotong $(8 \mathrm{~cm} \times 0,5 \mathrm{~cm})$ dari masingmasing sampel dan dipasang antara grip mesin. Kuat tarik ditentukan berdasarkan beban maksimum pada saat film pecah dan persentase pemanjangan didasarkan atas pemanjangan film saat film putus. Secara matematis hubungan tersebut dapat ditulis sebagai berikut :

$$
\text { Kuat } \operatorname{tarik}\left(\mathrm{N} / \mathrm{m}^{2}\right)=\frac{F}{A}
$$

Keterangan :

$\mathrm{F}$ : gaya kuat tarik $(\mathrm{N})$

A: luas penampang $\left(\mathrm{m}^{2}\right)$

$$
\text { Elongasi }(\%)=\frac{\Delta L}{L} \times 100 \%
$$

Keterangan :

$\Delta L$ : perpanjangan membran $(\mathrm{cm})$

$\mathrm{L}$ : panjang awal membran $(\mathrm{cm})$

\section{HASIL DAN PEMBAHASAN}

\section{Ekstrak Selulosa Pelepah Pohon Pisang}

Proses ekstraksi selulosa dilakukan dengan merefluks sampel pelepah pohon pisang dengan $\mathrm{NaOH} 4 \%$. Struktur kristalin lignin dan struktur amorf hemiselulosa dapat dirusak oleh $\mathrm{NaOH}$ sehingga sangat sesuai digunakan untuk menghilangkan lignin sekaligus mengekstraksi hemiselulosa. Umumnya produk serat yang dihasilkan pada proses delignifikasi oleh $\mathrm{NaOH}$ berwarna putih namun pada penelitian ini masih berwarna coklat. Sehingga dilakukan proses pemutihan agar warna serat menjadi lebih cerah atau putih.

Proses ekstraksi selulosa menghasilkan serbuk kering berwarna putih yang merupakan selulosa kasar. Rendemen selulosa dari pelepah pisang sebesar $62,5 \%$. Spektum IR selulosa murni memberikan puncak serapan di daerah bilangan gelombang pada 3350 $\mathrm{cm}^{-1}$ dimana puncak antara $3400 \mathrm{~cm}^{-1}$ $3500 \mathrm{~cm}^{-1}$ mengindikasikan adanya $\mathrm{O}-\mathrm{H}$ stretch, $2800 \mathrm{~cm}^{-1}-2900 \mathrm{~cm}^{-1}$ menunjukkan adanya $\mathrm{C}-\mathrm{H}$ stretching, $1160 \mathrm{~cm}^{-1}$ mengindikasikan adanya C-O-C stretching, dan $1035 \mathrm{~cm}^{-1}-1060 \mathrm{~cm}^{-1}$ mengindikasikan adanya C-O stretching. Pada daerah fingerprint selulosa memberikan puncak di sekitar $1300 \mathrm{~cm}^{-1}$ 
mengindikasikan adanya $\mathrm{C}-\mathrm{H}$ bending dan sekitar $1400 \mathrm{~cm}^{-1}$ mengindikasikan adanya $\mathrm{CH}_{2}$ bending (Marchessault dan Sundararajan, 1983). Hasil spektrum IR selulosa pelepah pisang menunjukkan adanya puncak pada $3423 \mathrm{~cm}^{-1}, 2854 \mathrm{~cm}^{-}$ 1, $1431 \mathrm{~cm}^{-1}, 1323 \mathrm{~cm}^{-1}, 1161 \mathrm{~cm}^{-1}$, dan $1020 \mathrm{~cm}^{-1}$. Hasil ini memiliki kemiripan spektrum IR dengan selulosa murni.

Menurut Kamal et al., (2014) karakterisasi ikatan selulosa pada spektrum papan serapan pada $3300-3500$ $\mathrm{cm}^{-1} \quad$ corresponding stretching menunjukkan gugus $\mathrm{OH}$. Ikatan serapan pada 2700-2900 $\mathrm{cm}^{-1}$ dicirikan dengan adanya gugus $-\mathrm{CH}_{2}(\mathrm{CH}$ streching $)$. Karakterisasi ikatan pada $1065 \mathrm{~cm}^{-1}$ untuk C-O-C (sambungan eter) dari unit glikosida.

Tabel 1 Bilangan Gelombang $\left(\mathrm{cm}^{-1}\right)$ selulosa

\begin{tabular}{ccccc}
\hline & \multicolumn{3}{c}{ Bilangan Gelombang $\left(\mathrm{cm}^{-1}\right)$} & \\
\cline { 2 - 4 } $\begin{array}{c}\text { No Selulosa } \\
\text { Murni }\end{array}$ & $\begin{array}{c}\text { Selulosa } \\
\text { Hasil } \\
\text { Penelitian }\end{array}$ & $\begin{array}{c}\text { Selulosa } \\
\text { (Kamal et } \\
\text { al., 2014) }\end{array}$ & $\begin{array}{l}\text { Gugus } \\
\text { Fungsi }\end{array}$ \\
\hline 1 & 3350 & 3423 & 3300 & O-H Ulur \\
2 & 2800 & 2854 & 2700 & C-H Ulur \\
3 & 1400 & 1431 & - & CH $_{2}$ Tekuk \\
4 & 1300 & 1323 & - & C-H Tekuk \\
5 & 1035 & 1020 & 1065 & C-O Ulur
\end{tabular}

\section{Selulosa Asetat Hasil Sintesis}

Proses asetilasi bertujuan untuk memproduksi selulosa asetat. Larutan untuk asetilasi ini diperoleh dari pemanasan dan pengadukan selulosa dengan menambahkan campuran asetat anhidrid yang berlebih 5-10\% (Mc.Ketta, 1982). Pada proses asetilasi ini, kebanyakan dari gugus hidroksil digantikan oleh gugus asetil. Pada esterifikasi yang komplit, mayoritas gugus hidroksil yang tersisa terikat dihidroksi primer pada selulosa.
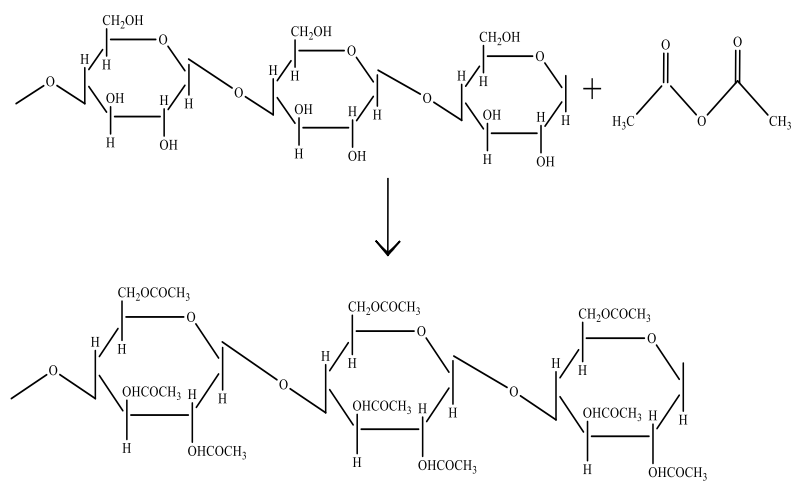

Gambar 1 Mekanisme reaksi asetilasi

Berat selulosa sebelum disintesis adalah 10 gram dan setelah proses sintesis diperoleh berat sampel 5 gram. Sehingga diperoleh rendemen selulosa asetat dari pelepah pisang sebesar $50 \%$. Rendemen selulosa asetat yang diperoleh pada penelitian ini lebih tinggi dibandingkan dengan rendemen selulosa asetat dari selulosa limbah agar yang dilakukan Nurhayati dan Rinta (2014), yang memperoleh rendemen sebesar $26,19 \%$.

Hasil analisis gugus fungsi menggunakan FTIR menunjukkan adanya puncak serapan gugus karbonil, $\mathrm{C}=\mathrm{O}$ (1749-1622 $\mathrm{cm}^{-1}$ ) dan gugus ester C-O dari gugus asetil $\left(1377 \mathrm{~cm}^{-1}\right)$ masingmasing pada bilangan gelombang 1749 $\mathrm{cm}^{-1}$ dan $1377 \mathrm{~cm}^{-1}$. Hal ini menunjukkan terbentuknya senyawa selulosa asetat dengan adanya puncak yang tajam pada 
bilangan gelombang $1749 \mathrm{~cm}^{-1}$ dan terjadi penurunan intensitas gugus $\mathrm{OH}$ akibat tersubstitusi oleh gugus asetil. Terlihat serupa, hanya saja gugus $\mathrm{OH}$ pada bilangan gelombang $3406.29 \mathrm{~cm}^{-1}$ dari selulosa asetat komersial memiliki serapan yang lebih tinggi dibandingkan selulosa asetat hasil sintesis. Puncak serapan khas dari selulosa asetat komersial maupun hasil sintesis dapat dilihat pada Tabel 2.

Tabel 2 Bilangan Gelombang $\left(\mathrm{cm}^{-1}\right)$ selulosa asetat

\begin{tabular}{ccccc}
\hline & \multicolumn{3}{c}{ Bilangan Gelombang $\left(\mathrm{cm}^{-1}\right)$} & \\
\cline { 2 - 4 } No & $\begin{array}{c}\text { Selulosa } \\
\text { Asetat } \\
\text { asetat } \\
\text { Komersial }\end{array}$ & $\begin{array}{c}\text { Selulosa } \\
\text { Nurhayati } \\
\text { dan Rinta, } \\
\text { 2014) }\end{array}$ & $\begin{array}{c}\text { Gugus } \\
\text { hasil } \\
\text { sintesis }\end{array}$ & Fungsi \\
\hline 1 & 3486.97 & 3632.20 & 3391,59 & O-H ulur \\
2 & 2960.38 & 2961.62 & 2901,7 & C-H alkana \\
3 & 1754.63 & 1755.90 & 1636,49 & C-O ulur \\
4 & 1383.89 & 1372.53 & 1027,02 & C-O-C ulur \\
\hline
\end{tabular}

\section{Berat Molekul Selulosa Asetat}

Penentuan berat molekul (BM) dari selulosa asetat dilakukan dengan metode kapiler atau Ostwald. Prinsip dari metode ini yaitu mengukur waktu yang dibutuhkan bagi cairan yang diukur untuk melewati dua tanda batas karena gaya gravitasi pada viskometer ostwald.

Berat molekul dari biopolimer selulosa asetat adalah parameter penting untuk menentukan sifatnya. Umumnya polimer dengan berat molekul tinnggi mempunyai sifat yang lebih khas dengan manfaat yang lebih cenderung pada pembuatan membran (Habibah et al., 2013).

Berdasarkan hasil penelitian diperoleh berat molekul selulosa asetat dari hasil sintesis selulosa pelepah pisang adalah 24.961,48 g/mol. Hasil tersebut lebih besar jika dibandingkan dengan penelitian sebelumnya Wijoyo (2002) dengan sampel Eucalyptus Alba yaitu $17.746 \mathrm{~g} / \mathrm{mol}$, tetapi lebih kecil dibandingkan dengan berat molekul selulosa asetat murni $30.000 \mathrm{~g} / \mathrm{mol}$.

Menurut Wijoyo (2002), beberapa faktor yang mempengaruhi berat molekul selulosa asetat adalah panjang serat dari selulosa/ bahan dasar, waktu proses perlakuan awal, waktu proses asetilasi dan waktu hidrolisis, komposisi bahanbahan yang digunakan dalam pembuatan selulosa asetat.

\section{Membran Selulosa Asetat}

Selulosa asetat diaplikasikan pada pembuatan membran dengan menambahkan pemlastis dengan tujuan meningkatkan elastisitas membran. Penambahan pemlastis PEG perlu dilakukan karena membran selulosa asetat yang dihasilkan tanpa pemlastis sangat rapuh sehingga tidak dapat dikelupas dari cetakan (Khaswar dan Tutus, 2014).

Membran yang dihasilkan berwarna putih transparan seperti plastik. Pada penelitian ini, sifat fisik membran diuji dengan pengukuran ketebalan membran, uji kuat tarik dan elongasi. 
1. Ketebalan

Ketebalan membran diukur menggunakan micrometer (ketelitian 0,001 mm). Ketebalan membran dipengaruhi oleh ketebalan lakban yang digunakan pada proses pencetakan. Tebal selotip yang digunakan adalah 0,036 mm. Rata-rata ketebalan membran dengan menggunakan konsentrasi PEG yang berbeda dapat dilihat pada Gambar 2

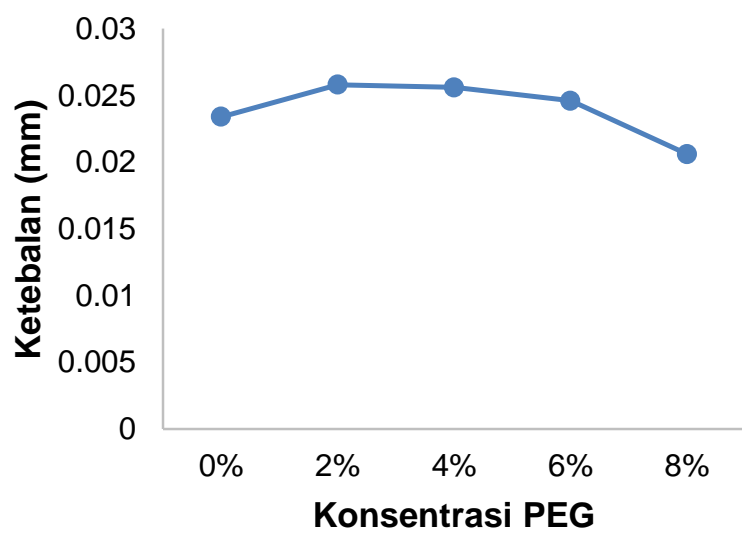

Gambar 2 Grafik Hubungan Konsentrasi PEG Terhadap Ketebalan Membran

Membran yang terbentuk dengan variasi konsentrasi PEG memiliki ketebalan yang beragam Hasil pengukuran rata-rata ketebalan (Gambar 2) menunjukkan bahwa peningkatan konsentrasi PEG cenderung meningkatkan ketebalan membran. Hasil uji ketebalan membran tertinggi adalah 0,0077 $\mathrm{mm}$ yang diperoleh pada konsentrasi PEG $2 \%$ dan yang terendah adalah 0,0059 $\mathrm{mm}$ pada konsentrasi PEG 0\%. Membran ini lebih tipis jika dibandingkan dengan membran berbahan dasar polimer agar-agar $(0,0167 \mathrm{~mm})$ (Setyaningrum et al., 2017). Ketebalan membran dapat mempengaruhi karakterisasi membran filtrasi (Mulder, 1996).

\section{Kuat Tarik}

Kuat tarik (tensile strength) merupakan gaya tarik maksimum yang dapat ditahan oleh sebuah film hingga terputus (Astuti,2008). Semakin besar kekuatan tarik maka membran semakin baik dalam menahan kerusakan mekanis. Rata-rata kekuatan tarik membran dengan penambahan konsentrasi PEG yang berbeda terlihat pada Gambar 3

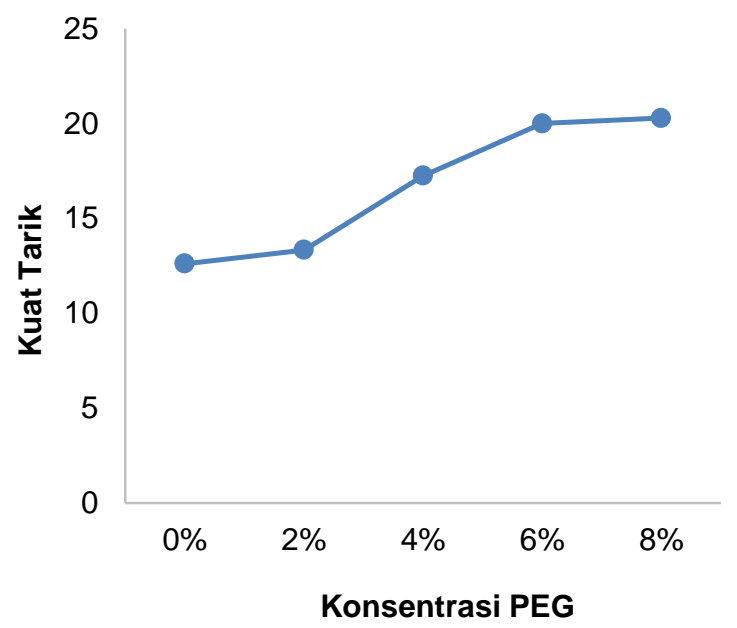

Gambar 3 Grafik Hubungan Konsentrasi PEG Terhadap Kuat Tarik Membran

Gambar 3 menunjukkan bahwa hasil uji kuat tarik membran tertinggi adalah 20,29 MPa yang diperoleh pada konsentrasi PEG 8\% dan yang terendah adalah $12,61 \mathrm{MPa}$ pada konsentrasi gliserol $13,3 \%$, sedangkan kontrol memiliki nilai kuat tarik sebesar 12,61 MPa. Hasil uji kuat tarik ini belum memenuhi standar minimal kuat tarik. Menurut Harrison et al., (2006), kuat tarik untuk membran selulosa 
asetat adalah $30 \mathrm{Mpa}$, sedangkan kuat tarik untuk membran polivinil klorida ada lah 20 Mpa.

Peningkatan nilai kuat tarik dipengaruhi oleh ukuran serat penyusun selulosa asetat. Semakin kecil ukuran serat penyusun selulosa asetat maka semakin tinggi nilai kuat tarik yang dihasilkan.

Hal ini sesuai pernyataan oleh Lu dan Kessler (2013), bahwa nanopartikel memiliki luas permukaan spesifik lebih besar daripada partikel ukuran mikron, molekul polimer lainnya akan teradsorpsi untuk menutupi permukaan nanopartikel dari massa yang sama sehingga mengurangi rongga pada material.

\section{Elongasi}

Elongasi diperoleh dari perbandingan pertambahan panjang maksimum membran dengan panjang awalnya (Pasla, 2006). Rata-rata nilai elongasi membran dengan penambahan konsentrasi PEG yang berbeda dapat dilihat pada Gambar 4.

Persentasi elongasi menunjukkan seberapa lebar luas membran yang dapat ditarik, elongasi menunjukkan fleksibilitas dari membran (Yuan et al., 2009). Ratarata kemuluran (elongasi) membran yang dihasilkan dengan perlakuan konsentrasi PEG adalah 1-3\%. Namun hasil ini masih belum memenuhi standar nilai elongasi membran menurut ASTM (1996), dimana membran maksimal memiliki nilai elongasi sebesar 30-45 \%. Hasil yang diperoleh juga lebih rendah dibandingkan jika menggunakan pemlastis gliserol pada membran agar-agar, yaitu 12,75\% (Setyaningrum et al., 2017).

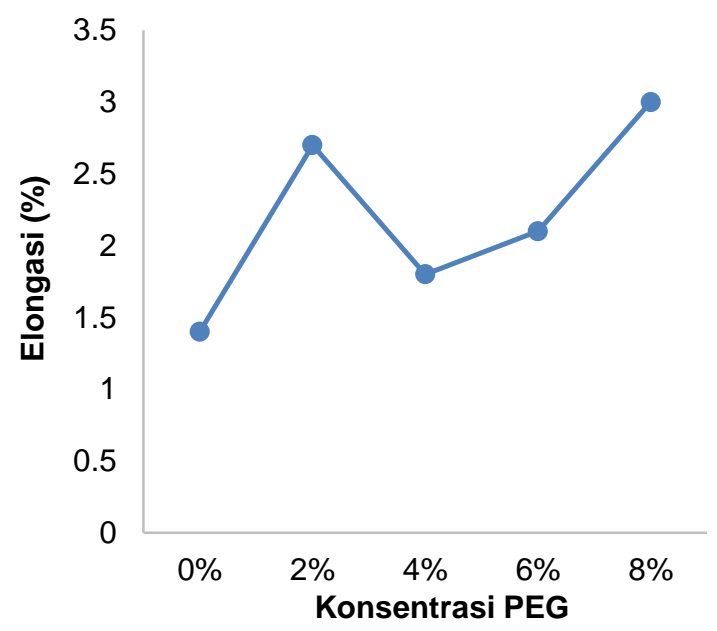

Gambar 4 Grafik Hubungan Konsentrasi PEG Terhadap Elongasi Membran

Peningkatan elongasi disebabkan oleh meningkatnya jumlah ikatan hidrogen yang terbentuk akibat pemlastis mengisi bagian pori-pori pada membran. Semakin tinggi ikatan hidrogen maka respon viskoelastisitas pun meningkat. (Bahmid et al., 2014).

\section{KESIMPULAN}

Berdasarkan hasil penelitian yang diperoleh, maka dapat disimpulkan bahwa rendemen selulosa yang diperoleh dari hasil ekstraksi adalah 62,5\% dan rendemen selulosa asetat yang diperoleh dari hasil sintesis adalah $50 \%$ dengan berat molekul 24.961,48 $\mathrm{g} / \mathrm{mol}$. Terbentuknya selulosa asetat ditunjukkan dengan hasil identifikasi FTIR berupa adanya serapan gugus karbonil $\mathrm{C}=\mathrm{O}$ pada bilangan gelombang $1749.44 \mathrm{~cm}^{-1}$ dan ester C-O dari gugus asetil $1377 \mathrm{~cm}^{-1}$ Ketebalan membran paling tinggi 
diperoleh pada konsentrasi PEG 2\% adalah 0,0258 $\mathrm{mm}$. Konsentrasi PEG terhadap selulosa asetat yang menghasiljan karakteristik membran terbaik adalah PEG 8\% dengan kuat tarik 20,29 Mpa dan Elongasi sebesar 3\%.

\section{DAFTAR PUSTAKA}

Akili, M.S., U. Ahmad, N.E. Suyatma. (2012). Karakteristik Edible film dari Pektin Hasil Ekstraksi Kulit Pisang. Jurnal Keteknikan Pertanian 26(1):39-46.

Apriliani, A P. (2010). Pembuatan dan karakteriasi membran kitosanpolietilen glikol (PEG serta apilkasinya pada penjernihan air sungai. Skripsi. Jakarta: Fakultas Sains dan Teknologi Universitas Pendidikan Indonesia.

ASTM. (1996). Standard test methods for tensile properties of thin plastic sheeting, D882-91. Annual book of ASTM. Philadelphia : American Society for Testing and Materials.

Astuti, B C. (2008). Pengembangan edible film kitosan dengan penambahan asam lemak dan esensial oil: upaya perbaikan sifat barrier dan aktivitas antimikroba. Skripsi. Bogor: Fakultas Teknologi Pertanian Institut Pertanian Bogor.

Bahmid, N A., Khaswar, S., Maddu, A. (2014). Pengaruh Ukuran Serat Selulosa Asetat Dan Penambahan Dietilen Glikol (DEG) Terhadap Sifat Fisik Dan Mekanik Bioplastik. Jurnal Teknologi Industri Pertanian, 24(3), 226-234.

Coutinho, Cesar de Morais. (2009). State of Art of the Apllications of Membrane Technology to Vegetable Oils. Brazil: State University of
Campinas Department of Food Technology Laboratory of Fats and Oils (LOG).

Darni, Y., Utami, H., Asriah, S. (2009). Peningkatan Hidrofobisitas dan Sifat Fisik Plastik Biodegradable Pati Tapioka dengan Penambahan Selulosa Residu Rumput Laut Eucheuma spinossum. Prosiding Seminar Hasil Penelitian dan Pengabdian Kepada Masyarakat. Lampung: Universitas Lampung.

Drioli, E., Lidietta, G. (2010). Comprehensive Membrane Science and Engineering. United Kingdom: Vol. 1 Elsevier B.V

Fadillah, F. (2003). Pengaruh penambahan Poli etilen glikol terhadap karakteristik membrane selulosa asetat. Tesis. Bogor: Fakultas teknologi pertanian IPB.

Habibah, R., Nasution, D Y., Muis, Y. (2013). Penentuan Berat Molekul Dan Derajat Polimerisasi A Selulosa Yang Berasal Dari AlangAlang (Imperata cylindrica) Dengan Metode Viskositas. Jurnal Saintis Kimia. 1 (2)

Harrison, I., Huttenhuis, P.J.G., Heesink, A.B.M. (2006). BIOCA-Biomass Streams to produce cellulose acetate. Department of Chemical Engineering Twente University Enschede Procede Twente BV Enschede. The Netherlands. Science in Thermal and Chemical Biomass Coversion. Edited by Bridgwater. A. V. dan Boocock, D. G. B. 1: 370-381

Kamal, A H., F. M. Abd-Elrahim B., Lotfy S. (2014). Characterization and Some Properties Of Cellulose Acetate-Co-Polyethylene Oxide Blends prepared by the use of gamma irradiation. Journal of 
Radiation Research and Applied Sciences. 7: 146-153

Khaswar, S., Kuryani, T. (2014). Pembuatan Biofilm Selulosa Asetat dari Selulosa Mikrobial Nata De Cassava. E-jurnal Agroindustr 3(1)

Kumano, A., Fujiwara, N. (2008). Cellulose triacetate membranes for reverse osmosis. $\mathrm{Li}$ et al. editor. Advanced membrane technology and applications. New Jersey: John Wiley\&Sons Inc. Page: 21-46.

Lankaster, M. (2002). Green Chemistry. RSC Paperbacks. Cambridge

Lu, K., Kessler, CS. (2007). Nanoparticle colloidal suspension optimization and freeze-cast forming. The American Ceramic Soc. 27 (8):110.

Marchessault, R. H., P. R. Sundarajan. (1983). Cellulose in : Aspinal, G. O. (editor) the polysacaride. London : Academic Press, Inc.

Mc.Ketta, J.J., Cunningham, W.A. (1982). Encyclopedia of Chemical Processing and Design Vol 16. NewYork.: Marcel Dekker Inc.

Mohammadi, T., Saljoughi, E. (2009). Effect of Production Conditions on Morphology and Permeability of asymmetric cellulose acetate membranes. Vol 243. hlm 1-7.

Mulder, M. (1996). Basic Principles of Membrane Technology, $2^{\text {nd }}$ ed. Dordrecht : Kluwer Academic Publisher.

Muliawati, E C. (2012). Pembuatan Dan Karakterisasi Membran Nanofiltrasi untuk Pengolahan Air. Tesis. Semarang: Universitas

Ningsih, A P., Nurmiati, Agustien A. (2013). Uji Aktivitas Antibakteri Ekstrak Kental Tanaman Pisang
Kepok Kuning (Musa paradisiaca Linn.) terhadap Staphylococcus aureus dan Escherichia coli. Jurnal Biologi Universitas Andalas (J. Bio. UA.) 2(3) : 207-213.

Nunes, P.S. (2001). Membrane Technology in the chemical industry. New York : Jon Willey \& Sons.

Nurhayati., Kusumawati, R. (2014). Sintesis Selulosa Asetat Dari Limbah Pengolahan Agar. JPB Perikanan Vol. 9 No.2 : 97-107

Pasla, F R. (2006). Pencirian Membran Selulosa Asetat Berbahan Dasar Selulosa Bakteri Dari Limbah Nanas. Skripsi. Bogor: Fakultas Matematika Dan Ilmu Pengetahuan Alam Institut Pertanian Bogor.

Rini, P A., Hastuti, R., Gunawan. (2008). Pengaruh Komposisi Poly Ethylene Glycol (PEG) Dalam Membran Padat Silika Dari Sekam Padi Dan Aplikasinya Untuk Dekolorisasi Limbah Cair Batik. Skripsi. Semarang: Jurusan Kimia, Fakultas MIPA,Universitas Diponegoro.

Rosli, N A., Ahmad, I., Abdullah, I. (2013). Isolation and Characterization of Cellulose Nanocrystals from Agave Angustifolia fibre. Bioressources. 8(2), 1893-1908

Saljoughi, E. (2010). Effect of PEG additive and coagulation bath temperatureon the morphology permeability and thermal/chemical stability of asymmetric CA membranes. Vol.262. hlm 72-78.

Setyaningrum, A., Sumarni, N. K., \& Hardi, J. (2017). Sifat Fisiko-Kimia Edible Film Agar-Agar Rumput Laut (Gracilaria sp.) Tersubtitusi Glyserol. Natural Science: Journal of Science and Technology, 6(2).

Su, Y.L., Cheng, W, Li, C, Jiang, Z. (2009). Preparation of antifouling 


$$
\begin{aligned}
& \text { ultrafiltration membranes with } \\
& \text { poly(ethylene glycol)-graft- } \\
& \text { polyacrylonitrile } \quad \text { copolymers. } \\
& \text { Elsevier. Journal of Membrane } \\
& \text { Science. Page : } 246-252
\end{aligned}
$$

Wijaya, A. (2002). Pengembangan Teknologi Papan Komposit Dari Limbah Batang Pisang (Musa sp) : Sifat Fisis Mekanis Papan Pada Berbadgai Tingkat Asetilasi . Skripsi. Bogor: Jurusan Teknologi Hasil Hutan. Institut Pertanian Bogor.

Wijoyo. (2002). Pembuatan dan Karakterisasi Membran Selulosa Asetat dari Pulp Eucalyptus Alba. Tesis. Bandung : Institut Teknologi Bandung.
Yang, L., Hsiao, W., Chen, P. (2001). Chitosan-cellulose composite membrane for affinity purification of biopolymers and immunoadsorption. Elsevier. Journal of Membrane Science. Vol 197. Page : 185-197.

Yuan, J., Dunn, D., Clipse, NM., Newton, Jr R J. (2009). Characterization of Cellulose Acetate Films : Formulation Effects on the Thermomechanical Properties and Permeability of Free Films abd Coating Films. Pharmaceutical Technology, V33, N3, pp0, 88-100. 